\title{
História Econômica e Demografia Histórica: um encontro marcado
}

com imenso prazer que apresentamos o dossiê História Econômica e Demografia Histórica. Preliminarmente, cabe esclarecer que, em virtude da grande demanda de artigos submetidos e aprovados, decidimos desdobrar o dossiê em dois números da revista Resgate: a Parte 1 , com a presente edição; composta por nove artigos, e a Parte 2, composta por outros dez textos, com publicação prevista para março de 2018. Ambas edições contam com contribuições de autores(as) prestigiados(as) nos campos da História Econômica e da Demografia Histórica, procedentes de diferentes universidades brasileiras.

O dossiê História Econômica e Demografia Histórica percorreu um longo caminho até chegar aos seus leitores. Começou com o convite feito pela pesquisadora Dra. Maria Elena Bernardes, então diretora do Centro de Memória - Unicamp (CMU), para organizarmos um grupo de trabalho no VIII Seminário Nacional do Centro de Memória, que culminou na proposição do GT Memória, História Econômica e Demografia, um dos 12 grupos de trabalho que integraram o evento. Após a realização do seminário, em julho de 2016, recebemos um novo convite para organizarmos o dossiê que ora se apresenta.

Nossa proposta é a interdisciplinaridade de duas áreas autônomas da História, tendo como objetivo potencializar a compreensão dos acontecimentos e das transformações sociais e econômicas que se passaram em espaços geográficos específicos e em tempos determinados. Partimos do pressuposto que o estudo da população é fundamental para entender os condicionamentos das transformações na vida material, na produção, distribuição e consumo de mercadorias, no trabalho, no dinheiro e no crédito. A história da população condiciona e é, ao mesmo tẹmpo, condicionada pelas estruturas e pelas condições sociais, econômicas e culturais que se modificam e voltam a se reestruturar no tempo, segundo a ação de homens e mulheres, das gerações que fazem surgir novas formas na organização social, cultural e material do espaço e da paisagem. Isso nos faz lembrar da professora Emília Viotti da Costa ${ }^{\top}$ e de sua concepção do fazer á História, que enfatiza a necessidade de partir do "pressuposto de que são os homens que fazem a história (e não as estruturas), se bem que a façam dentro de condições determinadas".

O dossiê História Econômica e Demografia Histórica reúne trabalhos de pesquisa que resultaram da análise crítica de documentos originais, sejam eles produzidos por instituições públicas ou privadas, administrativas, judiciárias ou eclesiásticas, tais como: registros paroquiais (batismo, casamento ébito), testamentos, inventários post mortem, recenseamentos populacionais, almanaques, entre outros, como, por exemplo, as correspondências ativas e passivas trocadas entre indivíduos.

As contribuições que integram ò dossiê evidenciam a incursão teórica e historiográfica sobre diver1 COSTA, Emília Viotti da. Da Senzala à Colônia. 5. ed. São Paulo: Unesp, 2010, p. 31. 
sos temas interdisciplinares: redes de negócios, de clientelas e relações familiares; características das famílias livres, escravas negras e indígenas, e imigrantes; experiências de mobilidade social e espacial; comportamentos e estratégias frente à morte; transformações das formas de riqueza, e composição da força de trabalho para espaços geográficos e temporais da história brasileira.

Abrimos esta edição da Resgate com uma homenagem a Maria Luiza Marcílio. O artigo de Ana Silvia Scott reporta a trajetória acadêmica dessa pesquisadora pioneira no campo da Demografia Histórica brasileira, cuja tese de doutorado, La ville de São Paulo: peuplement et population. $1750-1850^{2}$, éo marco inaugural do campo e completa seu cinquentenário em 2017.

Em seguida, destacamos o artigo de autoria de Renato Leite Marcondes e José Flávio Motta, que se debruça sobre a correspondência de Antonio da Silva Prado, mais tarde Barão de Iguape, na qual o comerciante e traficante de escravos organiza as transações do empreendimento de duas viagens a Moçambique para trazer africanos escravizados para os senhores de engenhos de São Paulo, no limiar da Independência do Brasil.

Um conjunto de cartas de um negociante português em Minas Cerais foi também a fonte documental empregada por Paula Teixeira Pinto para mostrar a formação de redes de clientela e de negócios que ligaram as duas principais praças mercantis nos fins do século XVIII e início do XIX-Minas Cerais e Rio de Janeiro.

O artigo de Dayane Carvalho Dias e Carmen Alveal traz uma análise dos registros paroquiais de batismo da Capitania do Rio Grande durante a Guerra dos Bárbaros (1681-1714), que marca a interiorização do povoamento no Rio Grande do Norte, o consequente embate entre colonizadores e indígenas, o aniquilamento da população masculina indígena e a crescente presença de escravos africanos em uma área não vinculada à agroexportação. Outros dois artigos utilizam os registros paroquiais como principais fontes para repensar o segundo império e a república. Agnaldo Valentin focaliza os batismos dos filhos de escravos nascidos após da Lei do Ventre Livre, os ingênuos, em quatro localidades do Vale do Paraíba paulista no período entre 1871 e 1888 , evidenciando semelhanças entre elas. Sergio Nadalin, ao retratạr as famílias de imigrantes alemães luteranos em Curitiba entre 1866 e 1939, analisa o comportamento reprodutivo de três gerações/ coortes, e a tendência à diminuição, no tempo, das concepções pré-nupciais.

Os inventários post mortem serviram como principal suporte documental para dois trabalhos com objetivos distintos. Lelio Luiz de Oliveira faz um estudo sobre os comportamentos e as estratégias dos indivíduos frente à morte na região nordeste de São Paulo, apontando os bens legados e os valores destinados aos rituais fúnebres, aos pobres e às instituições religiosas, inscritos em testamentos e inventários post mortem em finais do século XVIII e século XIX. Já Anndrea Tavares analisa a evolução das fortunas de imigrantes portugueses em Belém, Província do Crão-Pará, 
entre os anos de 1840 e 1909, período anterior e de consolidação da economia extrativa da borracha. A autora, com base nos autos cíveis de inventários, destaca a importante presença dos portugueses na rede mercantil da cidade.

Por fim, o artigo de Marcelo Cruz utilizá o Recenseamento Ceral do Império de 1872 e as informações veiculadas no Almanak da Província de São Paulo (1873) para analisar a constituição e a distribuição da força de trabalho de livres e escravos em um conjunto de localidades que compõem as duas principais regiões cafeeiras de São Paulo, o Vale do Paraíba e o Oeste Paulista.

O leitor poderá evidenciar a multiplicidade de temas e as distintas abordagens presentes nos artigos do dossiê, em que se mesclam as análises quantitativas e qualitativas, e avaliar os resultados que, certamente, enriquecerão o diálogo acadêmico.

Não podemos concluir esta apresentação sem expressar nosso mais sincero agradecimento a todos(as) que contribuíram para a realização deste número: autores(as) que compartilharam suas experiências, avanços e resultados de investigação; pareceristas convidados, pela generosa disponibilidade e seriedade para avaliarem os artigos; Fúlvia Conçalves, artista plástica e professora aposentada da Unicamp, que gentilmente cedeu o uso da obra "Humanidáde X" (Linogravura, 1978), que integra o acervo do Museu Olho Latino (Atibaia, SP), para utilização na capa desta edição; Profa. Dra. Ana Maria Reis de Coes Monteiro e Prof. Dr. Jefferson Picanço, respectivamente diretora e diretor associado do $\mathrm{CMU}$, além de editores da Resgate, pelo apoio institucional; Carlos Lamari, pelo cuidado com o projeto gráfico; e Juliana Oshima Franco, editora executiva da revista, pela revisão e supervisão.

Dra. Maria Alice Rosa Ribeiro

Dra. Maísa Faleiros da Cunha

Organizadoras 


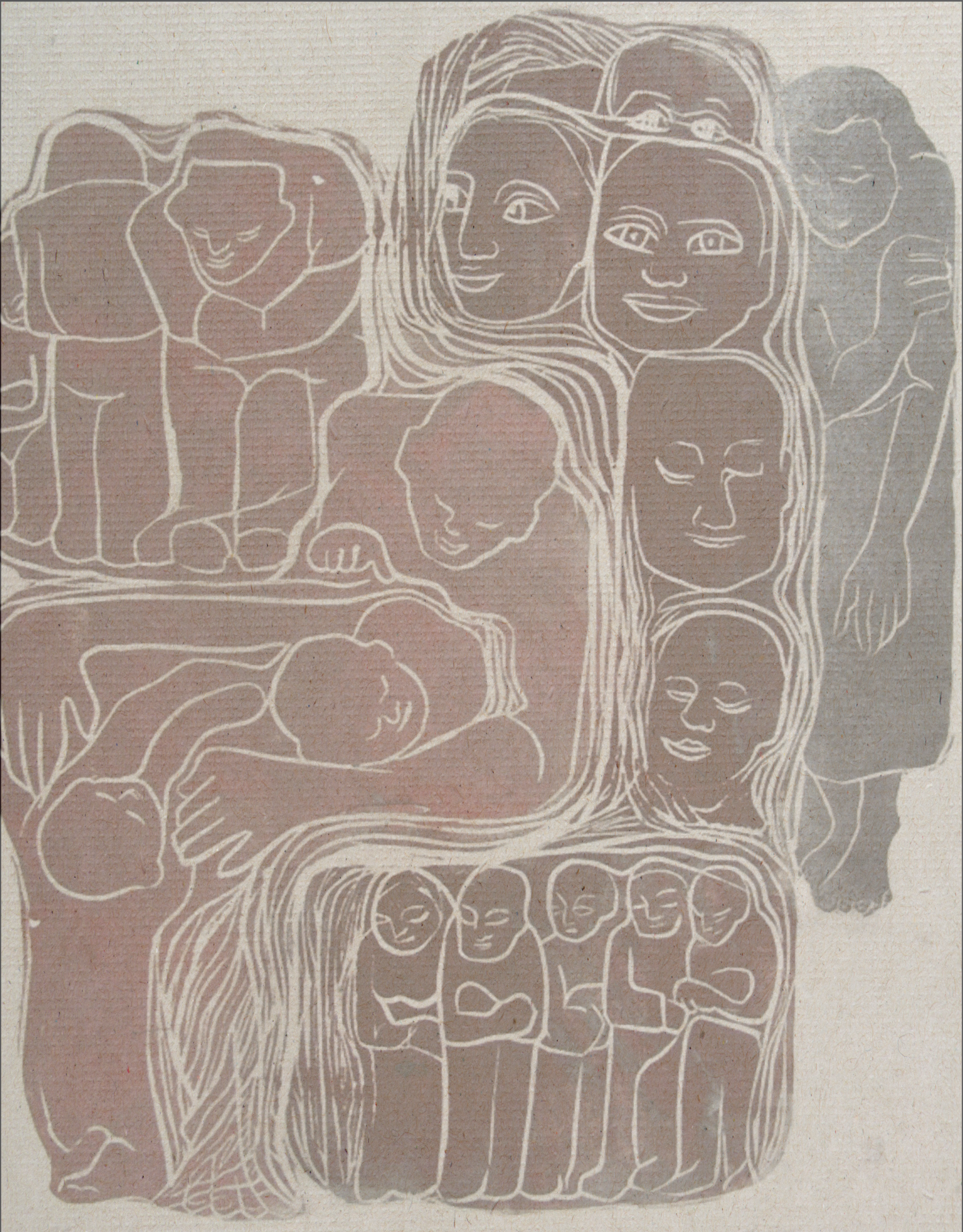

